\title{
THE CIRCUMLOCUTION FOR EFFECTIVE ENGLISH COMMUNICATIONS IN THE LEARNERS'S DAILY INTERACTIONS
}

\author{
Nungki Pamungkas ${ }^{1}$, Liliek Soepriatmadji ${ }^{2}$ \\ Faculty of Language and Cultural Studies, Stikubank University \\ e-mail: nungkipamungkas17@yahoo.com ${ }^{1}$, lilieksoepriatmadji@edu.unisbank.ac.id ${ }^{2}$
}

\begin{abstract}
The current study is aimed to find out the circumlocution especially the kinds and roles of circumlocution used by language learners in their daily interaction. In this research activity, the researcher apply the descriptive qualitative as a research tradition and based on the theory of circumlocution proposed by Arteaga \& Llorente (2012). The researcher analyze the gained data with five steps, those were reading the segmented utterances, identifying the utterances, categorizing the utterances that contain circumlocution, tabulating the result of the utterances, and interpreting the findings. In the findings, the researcher found that there are four kinds of circumlocution used by the learners and those were paraphrase, gestures, demonstrate, and switch the code. Paraphrase and gestures are dominant $(33,35 \%)$, followed by demonstrate $(26,68 \%)$ and switch the code $(6,67 \%)$. Alongside the kinds of circumlocution, the researcher also found two roles of circumlocution that were elaborations $(15,43 \%)$ and confident $(26,66 \%)$. From the data, the researcher concludes that language learners interact effectively and feel confident by applying paraphrase and gestures.
\end{abstract}

Keywords: Circumlocution, communication strategy, daily interaction

\section{INTRODUCTION}

This research started when the researcher found the problem which occured in the learners's interaction. Learners usually communicate with others to express their ideas. In order to elaborate the learners's idea, they have to make the communication works properly and effectively. Nowadays, most of the learners have an obstacle to make the communication works effective. They can not elaborate their idea in the proper way. Therefore, the communication among the learners did not works correctly.

In order to communicate, learners need to use a knowledge called as 'Communication Strategy' which could helped them to improve their communication skill and create a better interaction activity with other learners. In this research activity, the communication strategy which being focused and studied is called Circumlocution.

Circumlocution is a part of the communication strategy which allows the learners to 
elaborate their ideas with the longer utterances. It based on the lexical, diction, and the knowledge of the learners. Circumlocution has become the strategy which used in the daily interactions.

The research of circumlocution needs to be conducted because it can give a solution and information about communication especially among the language learners. When learners know about the communication strategy and they used it correctly, then the learners will not be stucked on communicating each other. The previous research about circumlocution has been conducted by Dobao (2007). Her research was about a collaborative process of face to face interactions easily created with the circumlocution. In this research, the researcher strengthen the argument of circumlocution as a communication strategy used by language learners in their daily interaction.

This research has a purpose to find out the kinds and roles of circumlocution inside the learners's daily interaction. The researcher also has limited the scope of the study, those were the circumlocution and the daily interaction. For the theories related to this research, the researcher has taken the theory of circumlocution proposed by Arteaga \& Llorente (2012) and theory of daily interaction proposed by Turner (1988).

\section{REVIEW OF RELATED LITERATURE}

The theories of communication strategy has become a need for every researcher who are willing to conduct the research about modern communication. One of the theory was proposed by Tarone (1980). She argued that circumlocution is categorized as a paraphrase which used by everyone. Meanwhile, Avval (2012) argued that communication strategies are those strategies that a language user or translator makes use of whenever she/he feel some differences in vocabulary and grammar leading to partial or complete misunderstanding or interruption in communication.

The theories used in this research activity were linguistically focused. There are so many theories about communication strategy but the researcher took only two which were really concentrated to the circumlocution.Circumlocution refers to as paraphrase, e.g., the thing you drink coffee from (for cup, as well as the use of analogy (e.g., foots for feet), a super-ordinate term (furniture for table), synonyms (car for auto), word coinage (warish for warlike). (Arteaga \& Llorente, 2012). Daily or social interaction is defined as a situation in which 
behaviour of one actor influence the behaviours of the others, and vice versa. (Turner, 1988).

\section{RESEARCH METHODOLOGY}

The researcher explains the research methodology in five steps to elaborated the ideas of this research paper. The research design started the research methodology, followed by unit of analysis, source of data, then the researcher elaborates the technique of data gathering and technique of data analysis.

This final project uses the field research as the research paradigm. The researcher take a data directly from the learners. For this circumlocution final project. The researcher applied the descriptive qualitative research as the research tradition. The way mean that the researcher classified and described the data. The unit analysis is concentrated on the learners's utterance because the circumlocution is being spoken by the learners during the research activity. For the source of data, the researcher has taken the data directly from the learners by himself and make sure that the data are really authentic. The researcher chose six university students to participate in this research activity which were three of them are Unisbank students and the other three are the students outside of Unisbank. Data gathering process took a step of interaction because the researcher asked the learners to answer the given questions from the researcher. After that, the researcher recorded their utterances, transcribing the data and segmenting the data which gained from the learners. When the researcher finished with the data gathering, the researcher started to analysing the data which begin with identifying and categorizing the data which contains circumlocution and then, to get the final data, the researcher tabulates and interprets the data.

\section{FINDING AND DISCUSSION}

This research paper has a final data of the learners's utterances which contain circumlocution. The researcher found out the kinds of circumlocution which being used by learners and the roles of circumlocution which appeared during the data gathering activity. The findings in this page are divided into two pictures of table which stand for kinds and also the roles of circumlocution which being shown in the following data below: 
Table 1 Kinds of Circumlocution

\begin{tabular}{|c|c|c|c|c|c|c|c|}
\hline \multirow{3}{*}{$\begin{array}{l}\mathbf{N} \\
\mathbf{0}\end{array}$} & \multirow{3}{*}{$\begin{array}{c}\text { Kinds of } \\
\text { Circumlocut } \\
\text { ion }\end{array}$} & \multicolumn{4}{|c|}{ Roles } & \multirow{3}{*}{ Total } & \multirow{3}{*}{$\%$} \\
\hline & & \multicolumn{2}{|c|}{ Elaborate } & \multicolumn{2}{|c|}{ Confident } & & \\
\hline & & $\mathrm{F}$ & $\%$ & $\mathrm{~F}$ & $\%$ & & \\
\hline 1 & $\operatorname{Pr}$ & 5 & 38.46 & & & 5 & 26.31 \\
\hline 2 & Gs & 2 & 0.15 & 4 & 40 & 6 & 31.58 \\
\hline 3 & Ds & 3 & 23.07 & 3 & 30 & 6 & 31.58 \\
\hline \multirow[t]{2}{*}{4} & Stc & 1 & 0.07 & 1 & 10 & 2 & 10.53 \\
\hline & Total & 13 & $100 \%$ & 10 & $100 \%$ & 19 & $100 \%$ \\
\hline
\end{tabular}

Notation:

$\mathrm{K} 1 \rightarrow$ Paraphrase

$\mathrm{K} 2 \rightarrow$ Gestures

$\mathrm{K} 3 \rightarrow$ Demonstrate

K4 $\rightarrow$ Switching the Code

In table 1 above, the researcher shows that the six university learners have performed circumlocution reflected from their utterances. Those six learners use four out of ten kinds of circumlocution. Learner 5 and 6 were fluently communicate with the researcher because they are language university students and they have a good knowledge about language which better than other four learners. Learner 2 and 3 performed three kinds of circumlocution

\begin{tabular}{|l|l|l|l|l|l|l|}
\hline No & k1 & K2 & K3 & K4 & Total & Total \% \\
\hline
\end{tabular}

which commonly used in their daily interaction meanwhile learner 1 and 4 performed only one kind of circumlocution because they did not have a good knowledge in communication.

Table 2 Roles of Circumlocution 


\begin{tabular}{|c|c|c|c|c|c|c|c|c|c|c|} 
& $\mathrm{F}$ & $\%$ & $\mathrm{~F}$ & $\%$ & $\mathrm{~F}$ & $\%$ & $\mathrm{~F}$ & $\%$ & & \\
\hline DT & 1 & 6.67 & & & & & & & 1 & 6.67 \\
\hline RSW & 1 & 6.67 & 1 & 6.67 & 1 & 6.67 & & & 3 & 20.01 \\
\hline MA & 1 & 6.67 & 1 & 6.67 & 1 & 6.67 & & & 3 & 20.01 \\
\hline GD & & & 1 & 6.67 & & & & & 1 & 6.67 \\
\hline RAM & 1 & 6.67 & 1 & 6.67 & 1 & 6.67 & & & 3 & 20.01 \\
\hline EL & 1 & 6.67 & 1 & 6.67 & 1 & 6.67 & 1 & 6.67 & 4 & 26.68 \\
\hline
\end{tabular}

Notation:

$\mathrm{K} 1 \rightarrow$ Paraphrase

$\mathrm{K} 2 \rightarrow$ Gestures

$\mathrm{K} 3 \rightarrow$ Demonstrate

$\mathrm{K} 4 \rightarrow$ Switch the code

In table 2 the researcher shows that there are two roles of circumlocution and those are elaboration and confident. The first role is circumlocution helping the learners to elaborate their ideas to the researcher and the second role is improving their confident to communicate because circumlocution can minimize the mistake of wrong utterances so that learners speak up without being afraid. From the table above, paraphrase is dominant in the first role meanwhile gesture is dominant in the second role.

\section{CONCLUSION AND SUGGESTION}

After conducting this research activity, the researcher could draw a conclusions which reflect the result of findings. Circumlocution is a part of communication strategy which allows learners to elaborate their ideas with the longer utterances and this kind of communication strategy used by the learners in their daily interaction. There are four kinds of circumlocution used by learners reflected in their utterances and there are two roles of circumlocution which found in this research activity. The daily interaction which occur among the learners consist of two different ways, those were written and spoken interaction. The daily interaction could be called as effective when the learners and interlocutor understand each other.

The researcher suggests that for the future research should find the data directly from the source of data because it could prevents the data manipulation. Future researcher has to consider the learners who participatein the research activity and choose them correctly. The 
future researcher should choose the learners who have a good communication skills and language knowledge so that the data could be rich in elaboration of circumlocution.

\section{BIBLIOGRAPHY}

Arteaga, D. \& L. Llorente. 2012. On The Importance of Circumlocution In The Spanish Language Classroom. Las Vegas. University of Nevada.

Aaron, P.G. \& R. Malatesha Joshi. 2006. Written Language Is as Natural as Spoken Language: A Biolinguistic Perspective. Indiana. Indiana State University

Al-Shemmary, I.M. \& Ubied, A.H. 2016. The Utilization of Circumlocution in Some Selected Religious Texts. 2016 vol. 18 no. 1 PP-38-43 University Press

Brennan, S.E. 2010. Conversation and Dialogue. PP-1 SAGE Publications.

Dornyei, Z. (1995). On the teachability of communication strategies. TESOL Quarterly, 29(1), 55-85.

Faerch, C., \& Kasper, G. (1983). Plans and strategies in foreign language communication. In C. Faerch \& G. Kasper (Eds.), Strategies in interlanguage communication.London: Longman.

Fernandez Dobao, A.M. 2007. The Use of Circumlocution Strategies in foreign language interaction: A Collaborative Creation of Meaning Process. Washington, D.C., University of Washington Seattle.

Maynard. Douglas W. \& A. Perakyla. 2006. Language and Social Interaction. New York: Plenum Publishers.

Obeng, S. (2012). "Language and Politics: Indirectness in Political Discourse " in Discourse Society January 1997 vol. 8 no. 1 PP-49-83 SAGE Publications.

Panocova, Renata. 2015. Categorize of Word Formation and Borrowing. Cambrige. Cambridge Scholars Publishing.

Rababah, G. (2005). Communication problems facing Arab learners of English. King Saud University, Riyadh, Saudi Arabia. Journals of language and learning, 3(1),180-197

Turner, Jonathan H. 1989. A Theory of Social Interaction. California. University of California. 